\title{
Programação no ensino de matemática utilizando Processing 2: um estudo das relações formalizadas por alunos do ensino fundamental com baixo rendimento em matemática
}

Eduardo Cardoso de Souza eduardoc@fc.unesp.br 0000-0002-8707-615X UNESP - Universidade Estadual Júlio de Mesquita Filho

Wilson Massashiro Yonezawa yonezawa@fc.unesp.br 0000-0003-3072-1506

UNESP - Universidade Estadual Júlio de Mesquita Filho

\section{RESUMO}

Este trabalho de cunho qualitativo investigou numa comunidade de prática de programadores as relações formalizadas por alunos com baixo rendimento em matemática, antes, durante e após participarem de oficinas de programação. Por meio da participação periférica legítima, buscou-se apontar como os alunos percebem a necessidade e/ou importância da matemática enquanto estão programando, quais são os conceitos matemáticos apropriados nessa construção, às relações estabelecidas, e as facilidades e/ou dificuldades durante esse processo. A pesquisa contou com oito oficinas e utilizou a ferramenta Processing 2. Da aprendizagem situada delinearam-se seis categorias de análise e tentou-se buscar subsídios para responder outros questionamentos como: Quais são as vantagens de aulas de matemática utilizando ferramentas de programação? Enquanto os alunos trabalhavam na solução dos desafios, estavam a "programar para aprender". À medida que se avançaram nas oficinas, os alunos aumentaram sua atitude reflexiva, de modo que a ferramenta passou a ser apenas um suporte.

PALAVRAS-CHAVE: Ensino de programação. Resolução de problemas. Pensamento matemático. Aprendizagem situada. 


\section{INTRODUÇÃO}

Atualmente, enquanto professor de Matemática do Ensino Fundamental e Médio, o autor deste trabalho tem vivenciado, no cotidiano escolar, um ensino da Matemática muitas vezes fragmentado e descontextualizado, desprovido de ligação entre a disciplina escolar e o mundo real, e que ainda despreza o uso de tecnologias.

As avaliações externas mostram resultados preocupantes em relação ao desempenho de alunos brasileiros em matemática. O relatório do Programa Internacional de Avaliação de Alunos (PISA), em 2012 aponta uma preocupação com o fato que não houve crescimento no número de estudantes nos níveis mais altos de proficiência, o que pode indicar que o país não está se preparando para formar adequadamente estudantes para funções mais complexas, que demandam conhecimento da matemática, como as áreas da engenharia e áreas afins (INEP, 2014).

Os indicadores do PISA não são diferentes daqueles que outras avaliações em larga escala têm apontado, como por exemplo, o Sistema de Avaliação do Rendimento Escolar do Estado de São Paulo (SARESP, 2015).

A partir desses resultados preocupantes, que colocam o ensino da matemática escolar no Brasil num patamar inferior, emerge o seguinte questionamento: o que fazer para mudar esse cenário? Uma resposta é evidente: o Brasil precisa encontrar formas de trabalhar com esses alunos de baixo rendimento e promover um ensino comprometido, atento as suas necessidades.

Com o advento da sociedade da informação e do conhecimento é praticamente impossível falar em construção do conhecimento e de um processo de ensino e de aprendizagem que despreza as influências das tecnologias, sendo sua utilização requisito fundamental no processo educacional para formação integral do aluno. Assim, este trabalho procura aproximar os alunos da alfabetização em programação.

Alguns pesquisadores, como Prensky (2005, 2008, 2010), Resnick (2012, 2013), Rushkoff (2012), sobre o futuro da educação discutem como seria a alfabetização no século XXI e questionam sobre quais são as principais habilidades que os indivíduos devem possuir para serem considerados alfabetizados.

Resnick (2013) enxerga a codificação (programação de computadores) como a nova alfabetização desse século, na qualidade de extensão da escrita. A programação não está substituindo a escrita, mas é bastante entrelaçada com ela e direciona para uma pedagogia mais abrangente.

A capacidade de codificação permite escrever novos tipos de coisas - histórias interativas, jogos, animações e simulações. Para Prensky (2008) o que distinguirá uma pessoa alfabetizada é a alfabetização em programação, a capacidade de fazer a tecnologia digital. Essa habilidade é conhecida como interação homem-máquina ou simplesmente programação.

A capacidade de escrever programas de computador é uma parte importante da alfabetização na sociedade de hoje. Quando as pessoas aprendem a programar, elas aprendem estratégias importantes para a resolução de problemas, projetos de design e comunicação de ideias (RESNICK, 2012). 
Segundo Rushkoff (2012) a alfabetização em programação é requisito para a participação em um mundo digital. Recentemente, as escolas ao redor do mundo têm se preocupado em realizar o letramento de suas crianças e adolescentes em uma "nova alfabetização". Crianças do ensino fundamental estão aprendendo fundamentos da lógica de programação por meio de jogos, plataformas online e ferramentas visuais, melhorando continuamente suas habilidades à medida que avançam por meio das séries. A ferramenta Scratch desenvolvida no MIT é um bom exemplo de apoio (RESNICK, 2009).

Atento às exigências na nova alfabetização do século XXI, no início de segundo semestre de 2014, escolas públicas da Inglaterra começaram a inserir seus alunos mais jovens no mundo da programação, acrescentando aulas obrigatórias de programação (BLOOMBERG, 2014).

Assim, considerando as dificuldades dos alunos brasileiros frente à aprendizagem matemática, os resultados ruins nas avaliações externas e a tendência da nova alfabetização, este trabalho tem como objetivo específico apontar como os alunos percebem a necessidade e/ou importância da matemática enquanto constroem "coisas". Identificar, à medida que os alunos aprendem programação, quais são os conceitos matemáticos implícitos nessa construção que os mesmos se apropriaram, as relações estabelecidas, e as facilidades e/ou dificuldades que demonstraram durante esse processo, bem como explorar a aprendizagem ativa em matemática, com feedback rápido.

A ferramenta utilizada foi o Processing 2, uma linguagem de programação de código aberto e um ambiente de desenvolvimento integrado (IDE), idealizado para as artes computacionais com o objetivo de ensinar os fundamentos da programação de computador em um contexto visual e para servir como a base para sketchbooks eletrônicos (PROCESSING, 2015).

\section{APRENDIZAGEM SITUADA}

A ideia de que a aprendizagem envolve um processo de participação numa comunidade de prática tem ganhado espaço significativo nos últimos anos. 0 termo comunidade de prática foi apresentado por Jean Lave, antropóloga, e Etienne Wenger, cientista da área computacional no livro Situated learning Legitimate peripheral participation em 1991.

A antropóloga social, Jean Lave da Universidade da Califórnia, em Berkeley, ao observar a atividade cotidiana, argumentou que "a aprendizagem é onipresente em toda atividade, embora muitas vezes não reconhecida como tal" (Lave, 1993, p.5). Assim, o argumento apresentado por Lave (1993) é que as comunidades de prática estão por toda parte: trabalho, escola, casa, ou em nossos interesses sociais e de lazer. Para Wenger (1998) comunidades de prática são formadas por pessoas que se envolvem em um processo de aprendizagem coletiva que compartilham uma paixão por algo que fazem e aprendem como fazê-lo melhor.

Carvalho e Steil (2012, p. 8) apresentam em seus trabalhos características e resultados da aprendizagem situada no ambiente organizacional. $\mathrm{O}$ aprendizado situado é cada vez mais envolvido com a tecnologia, em maneiras de ajudar as pessoas a aprender um conceito de forma diferente. A interação por meio do computador entre os indivíduos é mais uma maneira de fazer da aprendizagem 
situada bem-sucedida, assim como dar aos alunos uma oportunidade de ter outro local para aprender (HALVERSON, 2009).

A aprendizagem situada possibilita aos alunos participarem de situações autênticas, onde eles estão ativamente imersos em uma atividade ao usar a resolução de problemas (habilidades de pensamento crítico). Como implicações ocorrem: aperfeiçoamento profissional, soluções eficientes para as situaçõesproblemas, conhecimentos e geração de novas ideias.

Carvalho e Steil $(2012$, p. 8) elencam algumas características da aprendizagem situada, bem como das comunidades de prática, que puderam ser sintetizadas no esquema apresentado na Figura 1.

Figura 1 - Esquema da Aprendizagem Situada.

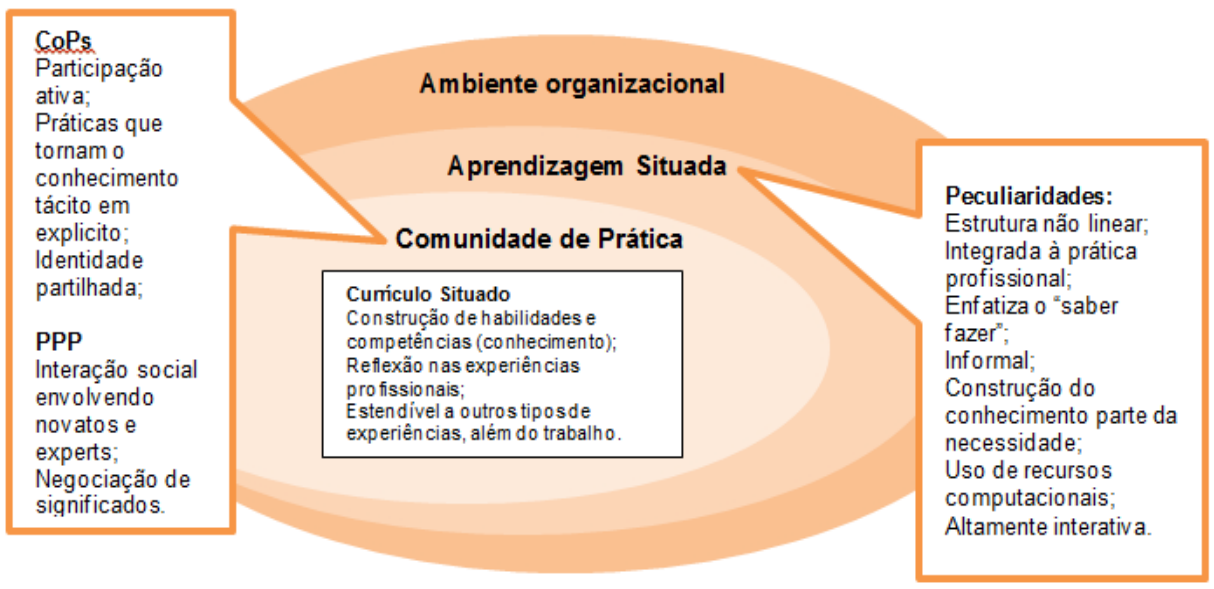

Fonte: Baseado em Carvalho e Steil (2012, p. 8).

Os estudantes que aprendem em uma comunidade de prática são capazes de usar com precisão as habilidades apropriadas por meio da experiência e preparados para serem produtivos em suas vidas.

Desta forma, compreender a teoria da aprendizagem situada em comunidades de prática formalizadas por Lave e Wenger (1991) e Wenger (1998), permitiu transformar os Laboratórios de Informática Educacionais (LIEs), em potenciais comunidades de prática de programadores, possibilitando a participação, enquanto membros periféricos legítimos.

As pessoas ingressam em uma comunidade como membros periféricos. À medida que os membros se tornam mais competentes, tornam-se mais envolvidos nos principais processos da comunidade particular. Assim, aprendizes novatos participam inevitavelmente em comunidades de praticantes e os conhecimentos e habilidades exigidos dos novatos movem-se em direção à participação plena nas práticas sociais de uma determinada comunidade (LAVE; WENGER, 1991, p.37).

Deste modo, os novatos começam a aprender observando os membros da comunidade e, em seguida, movem-se lentamente a partir da periferia da comunidade para participar plenamente como membros, em direção à liderança (Figura 2). 


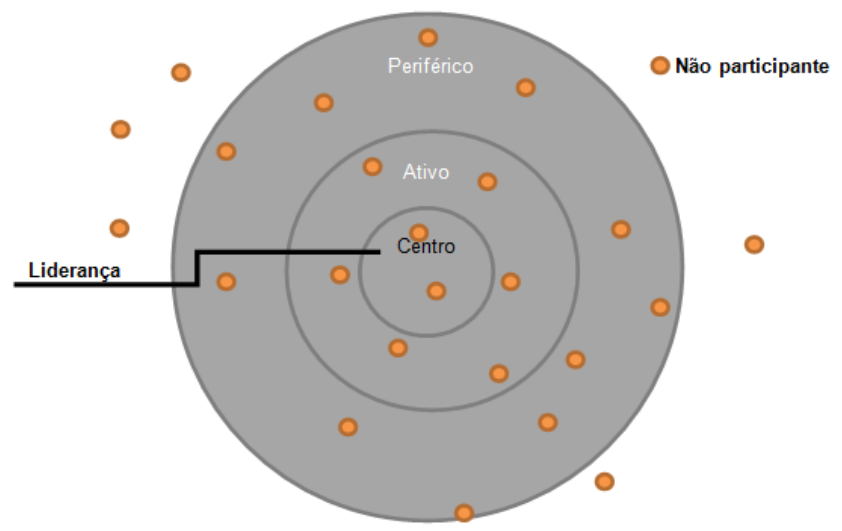

Fonte: Adaptado de Wenger (1998).

Para o aluno, ser membro periférico é altamente produtivo, uma vez que o aproxima de profissionais engajados, e ao observar suas práticas, atentar a suas elucidações será formalizado um envolvimento efetivo. Enquanto participante nas práticas de uma comunidade, cada membro define sua identidade, sua maneira de agir, pensar e se relacionar como membro.

O aprendizado situado está envolvido com tecnologia. A interação entre máquina e usuário se constitui em mais uma possibilidade de fazer da aprendizagem situada bem sucedida, e proporciona aos alunos uma oportunidade de se ter outro meio para aprendizagem (HALVERSON, 2009, p. 83).

Nossa sociedade pressupõe que muitos profissionais tenham seu local apropriado de trabalho. O bom desempenho de todo profissional depende também dos ambientes e dos instrumentos disponíveis. Para aqueles que possuem uma visão atualizada de educação matemática, os LIEs se configuram como ambientes favoráveis à criação de situações pedagógicas desafiadoras, por meio da formação de comunidades de prática de programadores.

Com isso, esperarmos que as discussões a serem levantadas na análise desta pesquisa promovam uma reflexão acerca da emaranhada rede de relações que se estabelecem numa comunidade de prática constituída por meio das oficinas de programação dentro dos LIEs e da maneira como os educadores e alunos constroem suas práticas e aprendem situados nesses espaços.

Recentes pesquisas têm procurado compreender a partir da teoria da aprendizagem situada cunhada por Lave e Wenger (1991) a aprendizagem situada da matemática em diferentes comunidades de prática, sob uma abordagem que envolve contexto, participação, engajamento, identidade e aprendizagem em CoPs.

Os trabalhos de Fernandes (2004) e Batista (2014) são exemplos encontrados na literatura. Fernandes (2004) procura identificar e caracterizar a atividade matemática dos alunos em práticas não socialmente definidas como Matemática (Práticas de Serralharia) e perceber como essa atividade estabelece vínculo ao currículo da Matemática escolar e ao seu desenvolvimento. Batista (2014) investiga quais aprendizagens são produzidas no interior de uma comunidade de aprendizes de matemática e como a identidade dos participantes se transforma, apropriando-se dos saberes e práticas da comunidade. 
Assim, este trabalho de pesquisa vem somar aos trabalhos apresentados por Fernandes (2004) e Batista (2014) e trará contribuições no campo da aprendizagem situada da matemática, uma vez que aborda questões relacionadas à aprendizagem de alunos com baixo rendimento em matemática em uma comunidade de prática de programadores, tendo como suporte um instrumento didático-pedagógico que é a programação de computadores articulada com a resolução de problemas que, após levantamento do estado da arte, parece não se encontrar na literatura em educação matemática com tanta frequência.

\section{PROGRAMAÇÃO DE COMPUTADORES COMO INSTRUMENTO DE ENSINO}

O emprego da programação como instrumento didático-pedagógico favorece a aprendizagem ativa, uma vez que a interação estabelecida entre as ações dos estudantes e o feedback do programa favorece a dinâmica. Nesta abordagem, o aluno descreve os passos necessários para atingir o objetivo, sendo direcionado a transformar seus conhecimentos em procedimentos (ALMEIDA, 2000).

Com o objetivo de possibilitar o uso pedagógico do computador em uma aproximação construcionista em detrimento da instrucionista, Papert (1986), desenvolve a linguagem de programação "Logo", que possibilita a criação de novas situações de aprendizagem que levam o aprendiz a refletir sobre o processo de construção.

O ensino dos princípios computacionais proporciona o desenvolvimento do pensamento computacional, que segundo Wing (2006) é uma habilidade fundamental para todos, não apenas para cientistas da computação e pode ser observada nos processos de leitura, escrita e matemática como parte integrante da habilidade analítica dos estudantes.

Pensamento computacional envolve a resolução de problemas, a concepção de sistemas, a compreensão do comportamento humano, construídos sobre os conceitos fundamentais da ciência da computação. Pensamento computacional inclui uma variedade de ferramentas mentais que refletem a magnitude do campo da ciência da computação (WING, 2006).

O pensamento computacional sistematiza os passos da solução de problemas, favorece a abstração e decomposição de uma tarefa complexa em que os alunos conseguem fragmentar os problemas da vida em partes funcionais para compreender o todo (WING, 2008). Assim, é um processo que inclui uma série de características, sendo essencial para o desenvolvimento de aplicativos de computador, mas também pode ser usado para apoiar a solução de problemas em outras situações ou em diferentes disciplinas, além das exatas, incluindo as humanidades.

Com isso, este trabalho também procura contribuir para o desenvolvimento do pensamento computacional dos estudantes. Para sistematizar algumas das características do pensamento computacional apresentadas por Wing (2006, 2008) foi elaborado um diagrama (Figura 3). 
Figura 3 - Características do pensamento computacional.

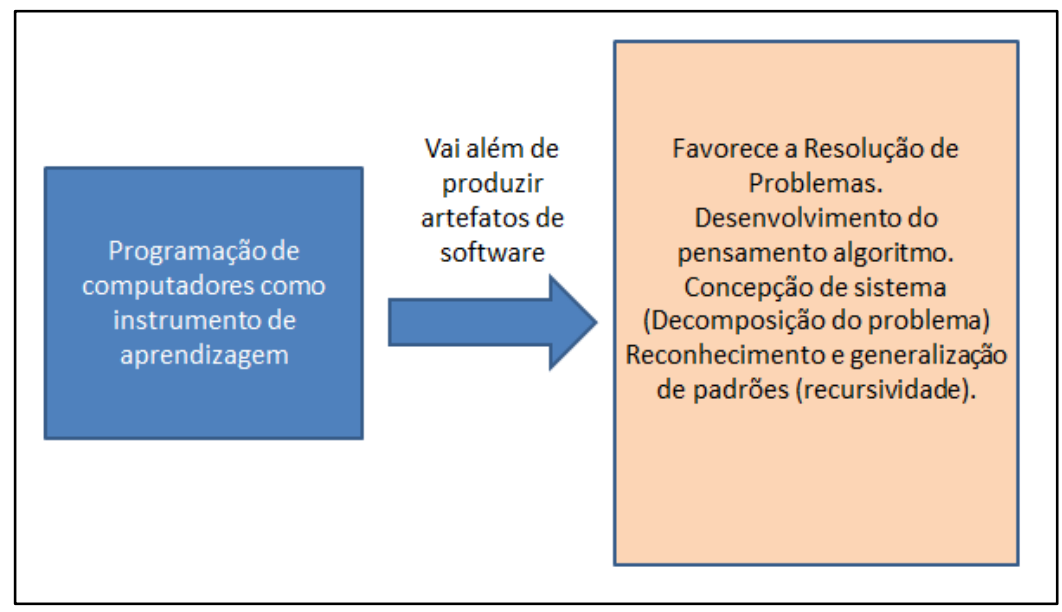

(Fonte: Autor (2016))

A proposta de Wing (2006) de resolver um problema aplicando o pensamento computacional significa reduzir grandes problemas em menores e mais simples de se resolver. Isso exige a capacidade de pensar de forma abstrata e em múltiplos níveis, e não apenas se restringe à aplicação de técnicas de programação. 0 pensamento computacional conjuga matemática e engenharia e representa a maneira que as pessoas pensam, gera ideias e não simplesmente artefatos de software e assim pode ser útil a todas as pessoas (WING, 2006).

Os trabalhos de Setti (2009) investigam o ensino e a aprendizagem de introdução à programação de computadores, focados na elaboração de algoritmos computacionais. A autora observa que alunos com conhecimentos matemáticos apropriados, encontram dificuldades na passagem do raciocínio matemático para o correspondente computacional. Na realização dessa passagem, a autora destaca que é necessário utilizar os conhecimentos matemáticos apropriados com um novo formato, devido ao processo de discretização necessário para transformar o raciocínio matemático no correspondente computacional e identifica aspectos de estruturas de repetição como necessárias para realizar o processo de particionar o todo em partes com menor complexidade.

Com isso, justifica-se a utilização da programação de computadores como instrumento de ensino que contribui para tornar o pensamento computacional difundido em nossas salas de aula, uma vez que pode desenvolver e aprimorar outras habilidades importantes conforme apresentadas.

\section{PROCESSING 2}

O Processing 2 é uma linguagem de programação visual, juntamente com um ambiente integrado de desenvolvimento. Ele não é o primeiro a seguir este paradigma. Como exemplo, o Logo apresenta esse contexto, quando um programador escreve instruções para dirigir uma tartaruga ao redor da tela, produzindo formas e desenhos. Ele é um descendente direto do Logo e nasceu em 2001 no grupo de pesquisa do Instituto de Tecnologia de Massachusetts Media Lab pela iniciativa dos estudantes de pós-gradução Casey Reas e Benjamin Fry. 
Processing 2 é usado por estudantes, artistas, designers, arquitetos, pesquisadores e entusiastas para aprendizagem, criação de protótipos e produção. Ele é criado para ensinar fundamentos da programação de computadores dentro de um contexto visual e para servir como um caderno de desenho de software e ferramenta de produção profissional (PROCESSING, 2015).

Assim, o Processing 2 atende a uma variedade de comunidades em diferentes contextos, desde a sala de aula do ensino fundamental até a universidade. Nos últimos anos, ele começou a se tornar uma presença na escola nas salas de aula do ensino fundamental e médio, sendo particularmente eficaz quando usado para ensinar ciência, matemática, e mais geralmente, ciência da computação (PROCESSING, 2015).

Um exemplo bem simples para que se possa entender o uso do Processing 2 no ensino de matemática é na construção de setores circulares, a ferramenta torna esse processo fácil.

O comando $\operatorname{arc}()$ é responsável por essa construção e possui a seguinte sintaxe: $\operatorname{arc~(a,~b,~c,~d,~início,~fim).~Os~parâmetros~necessários~a~serem~fornecidos~}$ nessa construção - a: coordenada $x$ do centro do setor circular; y: a coordenada y do centro do setor circular; c: a largura do raio do setor circular; d: a altura do raio do setor circular; início: ângulo para iniciar o arco em radiano; fim: o ângulo para terminar o arco em radiano.

As constantes PI e TWO_PI são comumente empregadas e equivalem a $180^{\circ} \mathrm{e}$ $360^{\circ}$, respectivamente. PI, QUARTER_PI, HALF_PI, e TWO_PI correspondem a $180^{\circ}$, $45^{\circ}, 90^{\circ}, 360^{\circ}$, respectivamente. Como exemplo, será construído um setor circular com área três quartos da circunferência. Uma das possibilidades de solução é o código apresentado na Figura 4.

Figura 4 - Exemplo de aplicação em matemática.

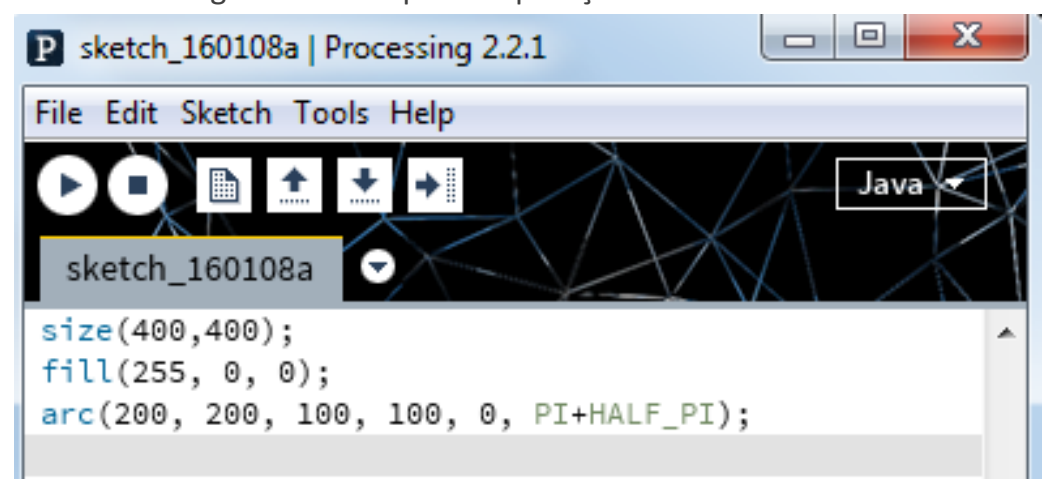

(Fonte: Autor (2016))

No código apresentado na Figura 4, o comando size define o tamanho da janela de apresentação. O comando Fill é responsável pelo preenchimento do setor circular, no caso do exemplo a cor vermelha é utilizada, e o comando arc é responsável pela construção do arco. Para conseguir um arco de $270^{\circ}$ como estratégia foi empregada a soma das constantes PI e HALF_PI. O resultado da execução do programa é apresentado na Figura 5. 
Figura 5 - Setor circular com área 3/4 da circunferência.

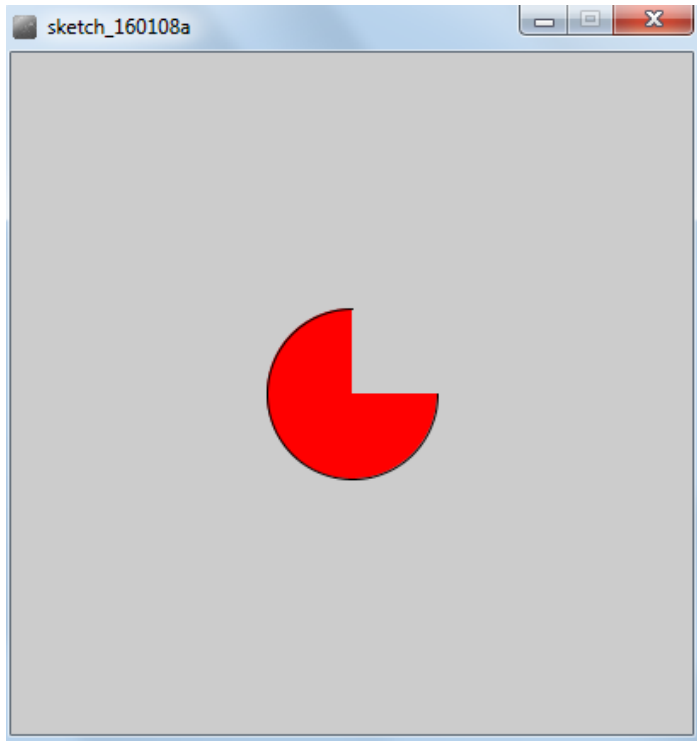

(Fonte: Autor (2016))

O exemplo apresentado foi uma pequena demonstração em relação às inúmeras potencialidades de criação que a ferramenta Processing 2 proporciona, que podem ser utilizadas em aulas de matemática.

O Ambiente de Desenvolvimento do Processing 2 consiste em um editor de texto simples para escrever código, uma área de mensagens, um console de texto, guias para gerenciamento de arquivos, uma barra de ferramentas com botões para as ações mais comuns, e uma série de menus (Figura 6).

Figura 6 - Ambiente integrado de desenvolvimento Processing 2.

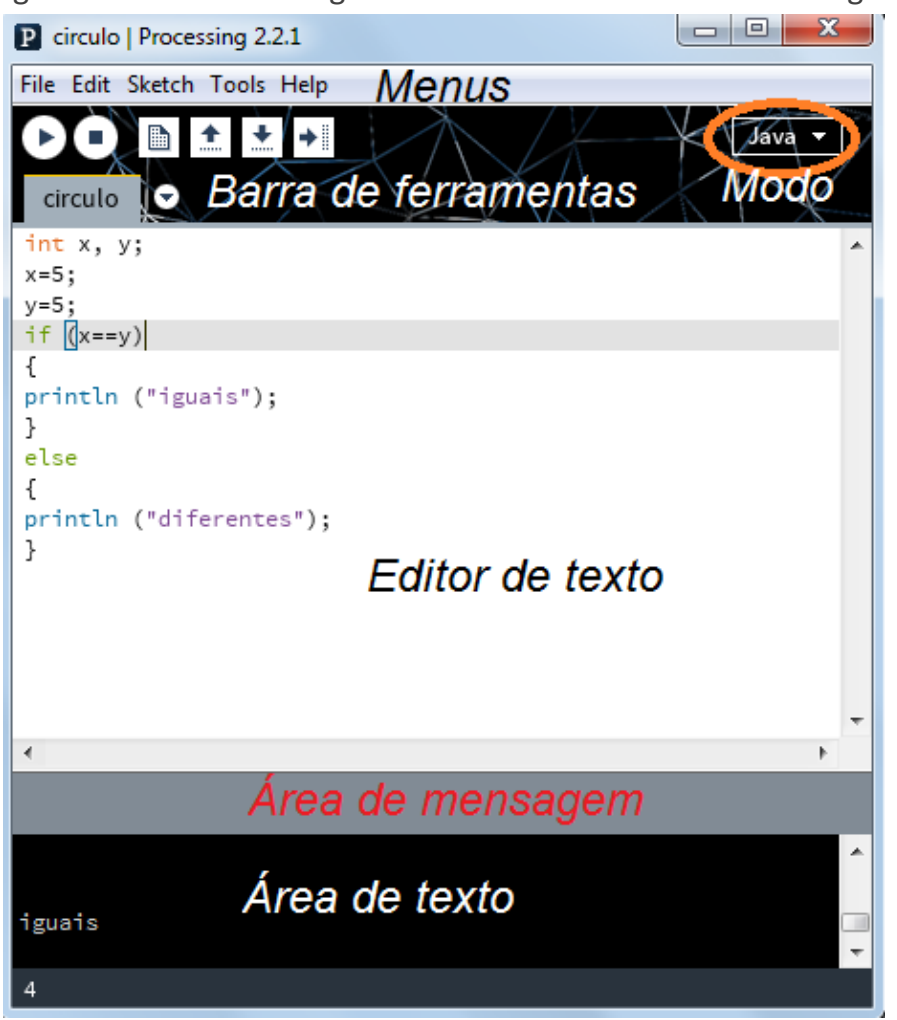


A linguagem Processing 2 foi projetada para gerar e modificar imagens, assim, o trabalho na ferramenta é realizado sob um sistema de coordenadas cartesianas com origem no canto superior esquerdo conforme apresentado na Figura 7.

Figura 7 - Sistema de coordenadas do Processing 2.

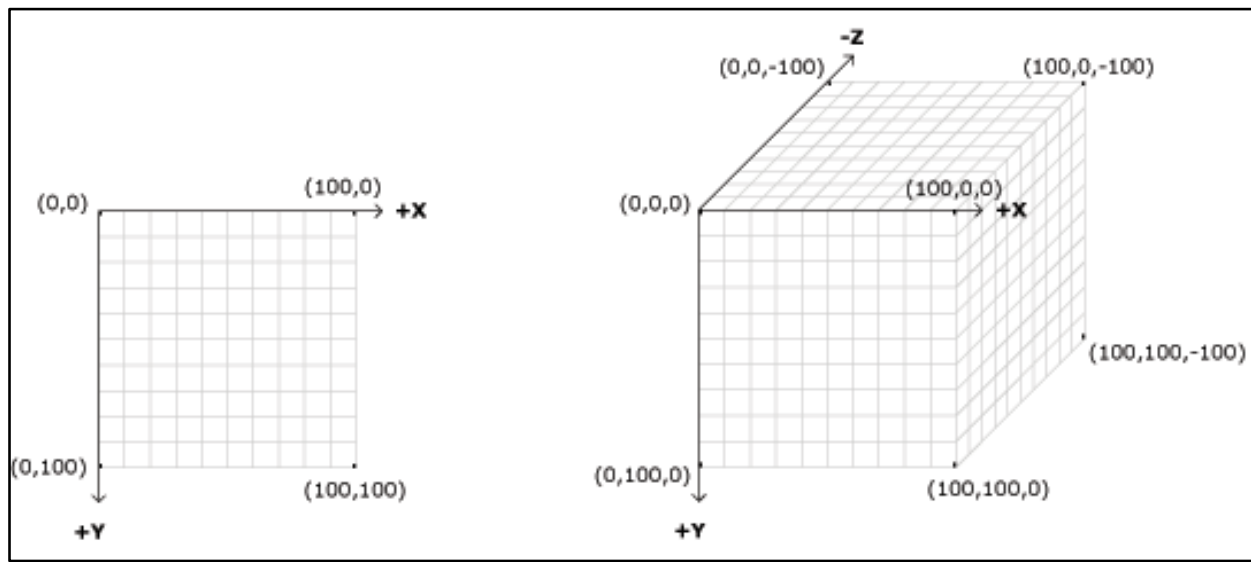

(Fonte: Processing (2016))

O software pode ser baixado gratuitamente na plataforma oficial da organização Processing (2015) e nela são fornecidas versões para Sistemas Operacionais Linux, Mac OSX e Windows. A ferramenta não necessita de uma instalação específica, bastando descompactar os arquivos em uma pasta elegida para guardar os arquivos do software.

\section{METODOLOGIA DA PESQUISA}

Este trabalho apresenta características de uma abordagem qualitativa, na qual se investigou as falas dos alunos e suas interações enquanto aprendiam programação de computador utilizando a ferramenta Processing 2.

Inicialmente, os alunos participaram de grupo focal, que consiste numa técnica que possibilita ao pesquisador observar a interação entre os participantes, proporcionando um ambiente mais natural se comparada à entrevista individual.

Segundo Gatti (2005) o grupo focal como técnica exploratória possibilita a realização de um estudo preliminar do objetivo principal da pesquisa, de modo que a investigação subsequente possa ser concebida com maior compreensão, delineamento e refinamento.

Para a realização da pesquisa foi escolhida uma escola de Ensino Fundamental do município de Santa Cruz do Rio Pardo - SP que contempla Laboratório de Informática Educacional (LIE). O software Processing 2 foi obtido gratuitamente e instalado em computadores com o sistema operacional Linux Educacional versão 3.0.

Para seleção dos sujeitos da pesquisa, foi solicitado que a professora de matemática das turmas do $7^{\circ}$ ano do período vespertino apontasse seis alunos que apresentassem baixo rendimento na disciplina. Assim, a seleção ficou a critério da professora de matemática e os estudantes aqui representados por CA, KA, MB, NB, TS e VH. 
E por que alunos com baixo rendimento? Tomando por base uma curva de distribuição normal, o grande desafio é trazer os alunos que se encontram nas extremidades dessa curva para a região do desvio padrão da média. Ensinar um aluno bom é na maioria das vezes fácil e o grande desafio consiste em fazer com que o aluno do nível abaixo do básico, ou básico se torne um aluno adequado, que demonstre domínio pleno de habilidades e competências desejáveis para o ano/série escolar em que se encontra (SARESP, 2015).

Os estudantes participaram de oito oficinas de programação, que transcorreram no período da manhã com duração prevista de três horas cada. Após as etapas de coleta dos dados, foram realizadas as compilações à luz dos referenciais deste trabalho e sob as categorias de análise, que serão descritas posteriormente.

As etapas da pesquisa foram pensadas previamente conforme síntese apresentada no quadro 1.

Quadro 1 - Etapas da pesquisa.

\begin{tabular}{|c|l|}
\hline $\begin{array}{c}\text { Grupo focal } \\
\text { Inicial }\end{array}$ & Como os estudantes enxergavam a matemática inicialmente? \\
\hline Oficina $\mathbf{1}$ & Introdução ao Processing 2 - características e noções iniciais. \\
\hline Oficina $\mathbf{2}$ & Formas primitivas e Sistema de coordenadas. \\
\hline Oficina 3 & Variáveis e condicionais. \\
\hline Oficina $\mathbf{4}$ & Função draw( ). \\
\hline Oficina 5 & Variáveis do sistema. \\
\hline Oficina 6 & Operadores lógicos. \\
\hline Oficina 7 & Movimentação (keyPressed). \\
\hline Oficina 8 & Aplicação dos conceitos apropriados anteriormente. \\
\hline Grupo focal final & $\begin{array}{l}\text { Como os estudantes passaram a enxergar a matemática após } \\
\text { as oficinas de Programação utilizando Processing 2. }\end{array}$ \\
\hline
\end{tabular}

(Fonte: Autor (2016))

As oficinas de Processing 2 foram ministradas por este pesquisador, por exigir conhecimento de lógica de programação e conhecimento da ferramenta empregada na pesquisa.

Para apoiar o planejamento das oficinas, utilizou-se como base, o tutorial descrito no texto "Getting Started with Processing", devidamente adaptado para a língua portuguesa que conta com diversos exemplos de programas e comentários. O manual foi projetado para ser usado tanto como um texto de apoio para um curso de programação de nível introdutório ou para autoinstrução.

Utilizou-se da análise de conteúdo para identificar características da aprendizagem situada na comunidade de prática constituída.

Segundo Bardin (2011) a análise de conteúdo conduz entre dois polos: a precisão da objetividade e a riqueza da subjetividade. Consiste em uma técnica refinada, que busca um texto atrás de outro texto, um texto que não está evidente em uma primeira leitura objetiva e que precisa de uma metodologia para ser revelado e isso exige do pesquisador dedicação e um certo grau de imaginação e criatividade, sobretudo na definição das categorias de análise.

As categorizações são classes que reúnem um grupo de elementos sob um título genérico, promovendo a organização em razão de características comuns. 
Assim, o que possibilita o agrupamento é a parte comum entre os elementos e a categorização tem como objetivo fornecer uma representação simplificada dos dados brutos (BARDIN, 2011).

Assim, foram delineadas seis categorias de análise, conforme os objetivos da pesquisa, que sinalizam arranjos da aprendizagem situada numa comunidade de prática de programadores, apresentadas resumidamente no quadro 2 :

Quadro 2- Categorias de análise.

\begin{tabular}{|c|c|}
\hline Categoria & Descrição resumida \\
\hline Não linearidade & $\begin{array}{l}\text { Um ambiente de aprendizagem situado } \\
\text { fornece aos estudantes a oportunidade de } \\
\text { investigar várias perspectivas (Wenger, } \\
\text { 2008). Possibilitar aos alunos múltiplos } \\
\text { papéis e oportunidades para explorar o } \\
\text { programa a partir de várias perspectivas } \\
\text { implica ricas situações de aprendizagem. }\end{array}$ \\
\hline Ênfase no "Saber Fazer" & $\begin{array}{l}\text { De acordo com Wenger (1998) esta } \\
\text { maneira de abordar a aprendizagem é algo } \\
\text { mais do que simplesmente "aprender } \\
\text { fazendo" ou aprendizagem baseada na } \\
\text { experiência e o conceito de } \\
\text { contextualização envolve pessoas que } \\
\text { sejam participantes plenos no mundo e na } \\
\text { geração de significado. }\end{array}$ \\
\hline Informal & $\begin{array}{l}\text { A despreocupação com um modelo ou } \\
\text { currículo pré-definido promove um } \\
\text { relacionamento mais favorável à } \\
\text { aprendizagem do que em relações de } \\
\text { hierarquia explícita (LAVE; WENGER, } \\
\text { 1991). }\end{array}$ \\
\hline $\begin{array}{l}\text { Construção do conhecimento parte da } \\
\text { necessidade }\end{array}$ & $\begin{array}{l}\text { Um ambiente de aprendizagem situado } \\
\text { fornece um contexto autêntico que reflete } \\
\text { a forma como o conhecimento vai ser } \\
\text { usado na vida real, a partir de uma } \\
\text { necessidade, que preserva o contexto } \\
\text { completo da situação sem fragmentação e } \\
\text { decomposição, que convida à exploração e } \\
\text { permite a complexidade natural do mundo } \\
\text { real (WENGER, 2008). }\end{array}$ \\
\hline Interatividade & $\begin{array}{l}\text { A interação entre máquina e usuário se } \\
\text { constitui em mais uma possibilidade de } \\
\text { fazer da aprendizagem situada melhor } \\
\text { sucedida, bem como proporcionar aos } \\
\text { alunos uma oportunidade de se ter outro } \\
\text { meio para aprendizagem. } \\
\text { A interatividade é um princípio básico de } \\
\text { sistemas computacionais por meio do } \\
\text { retorno ao usuário sobre as ações que } \\
\text { foram executadas e seus resultados } \\
\text { obtidos. }\end{array}$ \\
\hline Engajamento & $\begin{array}{l}\text { O engajamento consiste nos processos } \\
\text { internos em integraroaspecto subjetivo da } \\
\text { comunidade, assimilar sua língua, } \\
\text { conhecer suas histórias e proceder como }\end{array}$ \\
\hline
\end{tabular}




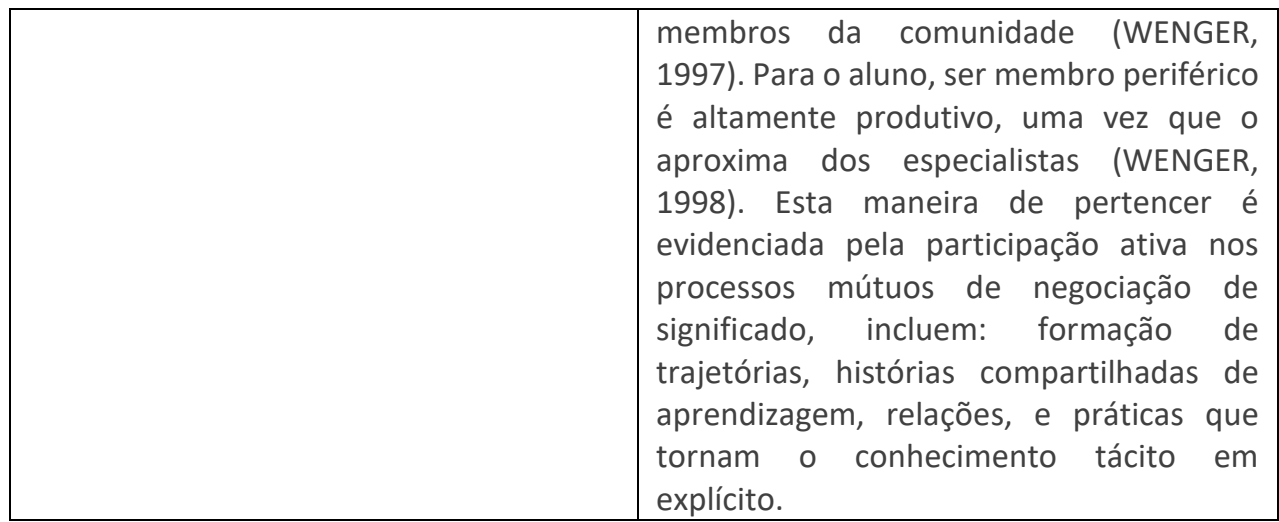

(Fonte: Autor (2016))

Para sintetizar o caminho metodológico percorrido neste trabalho, foi construído um diagrama que fornece uma visão geral (Figura 8), o que nos permite observar toda a trajetória metodológica realizada neste trabalho, desde o questionário semiestruturado até a apresentação dos dados e discussão dos resultados.

Figura 8 - Caminho metodológico percorrido

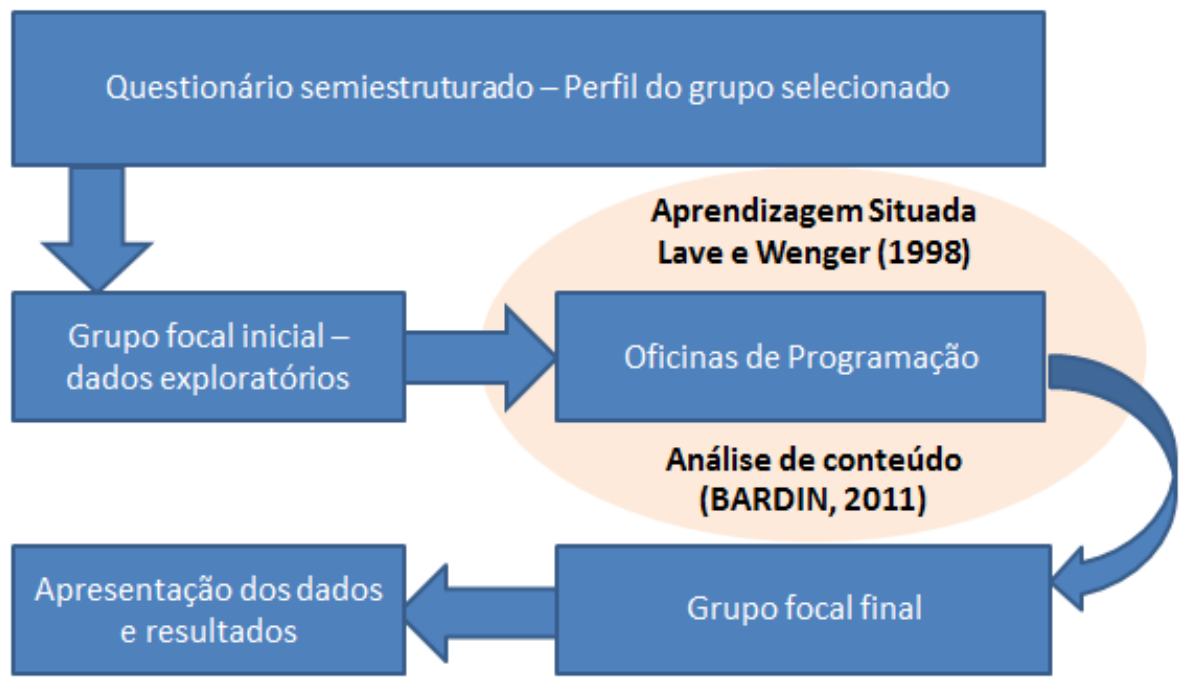

(Fonte: Autor (2016))

\section{APRESENTAÇÃO DOS DADOS E DISCUSSÃO}

Antes de iniciar os alunos na ferramenta Processing 2, os mesmos foram convidados a se sentarem em círculo para realização do grupo focal. Um dos primeiros diálogos em foco foi sobre a motivação/desmotivação em estudar matemática. $\mathrm{O}$ quadro 3 apresenta as interações na ordem proferida.

Quadro 3 - Motivação/desmotivação em estudar matemática. tarefa de casa, dá muita preguiça".

MB "Sabe, eu fico desmotivado em aprender matemática toda vez que tenho que aprender um assunto que não gosto. A professora nunca diz pra que serve aquilo. Agora o que mais me motiva é quando eu tiro nota boa na prova". 
VH $\quad$ "Eu fico sempre desmotivado quando não consigo entender o que a professora explica, matemática é legal, mas às vezes é difícil. Quando é facinho e eu consigo entender, daí eu gosto".

(Fonte: Primária (2016))

Como fator desmotivador é observado a grande quantidade de exercícios na tarefa de casa. Percebemos na fala da aluna TS que o excesso de exercícios propostos para casa é motivo de desmotivação. $O$ ensino apostilado impõe ritmos de aprendizagem e propõe tarefas de casa ao final de cada módulo, muitas vezes extensas, o que representa um indicativo de desmotivação.

Sobre a dificuldade de compreensão da explicação do professor demonstrada na fala do aluno $\mathbf{V H}$, enfatiza-se que o professor deve apresentar um pluralismo metodológico considerando o pressuposto que os alunos aprendem de diferentes formas e em ritmos diferentes. Assim, todo aluno pode aprender desde que the sejam oferecidas condições adequadas; isso implica considerar que não existe aluno incapaz e que variadas condições e caminhos devem ser disponibilizados para que o aluno aprenda. Segundo Almeida (2000) as crianças têm diferentes habilidades e, por isso, diversas maneiras e ritmos para aprender. Em um curto período de tempo, eles podem superar um problema familiar ou adquirir mais segurança com a ajuda de um professor e esses fatores repercutem profundamente na sua capacidade de aprender.

Na fala do aluno MB há indícios de problemas na formação do professor, quando ele diz: "a professora nunca mostra pra que serve aquilo". Isso pode representar um despreparo na formação inicial do professor, configurando num indicativo para a melhoria da formação continuada do mesmo.

Outra temática abordada no grupo focal inicial foi sobre as motivações dos alunos em relação ao uso das tecnologias e informática que serão apresentadas no Quadro 4.

Quadro 4 - Motivação dos alunos em relação ao uso de tecnologias.

\begin{tabular}{c|l}
\hline KA & $\begin{array}{l}\text { "Eu gosto muito da tecnologia e da informática. Eu gosto de mexer muito no } \\
\text { meu celular e eu acho que minha maior motivação é ficar mais atualizada". }\end{array}$ \\
\hline TS & $\begin{array}{l}\text { "Eu gosto de usar, principalmente ficar na internet, eu não me canso de mexer, } \\
\text { minha mãe precisa pedir pra eu desligar o computador". }\end{array}$ \\
\hline NB & $\begin{array}{l}\text { "Eu uso a internet para fazer pesquisa da escola. Eu gosto de ficar na internet e } \\
\text { eu entro no facebook e tem muita coisa legal". }\end{array}$ \\
\hline MB & $\begin{array}{l}\text { "Eu pretendo fazer uma faculdade que vai mexer com esse ramo (tecnologia). } \\
\text { Eu não me canso de mexer, na minha casa é o lugar que eu mais gosto de ficar". }\end{array}$ \\
\hline VH & $\begin{array}{l}\text { "Tudo de tecnologia motiva mais porque a gente não vê o tempo passar quando } \\
\text { tá usando. Eu mesmo fico baixando muita coisa, ontem eu baixei no meu } \\
\text { Andróide o Perguntados". }\end{array}$ \\
\hline CA & $\begin{array}{l}\text { "Eu gosto da tecnologia, principalmente dos jogos, eu fico lá jogando, ouvindo } \\
\text { músicas e vendo vídeo no youtube". }\end{array}$ \\
\hline
\end{tabular}

(Fonte: Primária (2016))

Nesta matéria evidencia-se a motivação dos alunos em relação à tecnologia, 
motivação intrínseca, externada nas expressões "coisa legal", "baixei no meu Andróide", "não me canso de mexer".

O estudante VH demonstra ter conhecimentos sobre o tipo do sistema operacional do seu smartphone, e aponta que instalou o aplicativo "Perguntados". Tal aplicativo é um jogo de perguntas e respostas sobre conhecimentos gerais e aborda diversas áreas, como ciências, esportes, entre outras. $O$ último aluno a manifestar sua opinião nesse eixo foi o aluno $\mathbf{C A}$, que manifesta sua motivação intrínseca por games virtuais.

Identifica-se que a resposta à pergunta, como os alunos gastam seu tempo, está relacionada a tecnologias e Internet, entre elas games digitais e vídeos online. Assim, traça-se o perfil de um grupo que pertence a uma geração com muita habilidade com tecnologia, mas mesmo assim tem notas baixas em matemática.

Após a realização do grupo focal inicial, que teve como objetivo compreender como os alunos participantes enxergavam a matemática inicialmente, os mesmos iniciaram a participação nas oficinas de programação.

A oficina 1 teve como objetivo apresentar a ferramenta de estudo da pesquisa aos estudantes, suas características, principais funcionalidades e uma exploração inicial do sistema de coordenadas da área de trabalho do Processing 2. A segunda oficina tinha como propósito ampliar a apropriação técnica na ferramenta e consistiu na exploração dos comandos de formas geométricas primitivas em 2D, entre os quais destacam-se: rect() ellipse(), line().

Antes do início da terceira oficina os alunos exploravam as habilidades apropriadas nas oficinas anteriores e alguns estudantes se destacavam como líderes, como os alunos MB, KA e TS. A aprendizagem situada prevê a presença social dentro da comunidade de prática, conforme apontados por Wenger (2000). Enquanto professor de matemática nos anos finais do Ensino Fundamental, quando se chega a uma sala de aula é sempre um grande desafio motivar os alunos para iniciar a aula e fazer com que eles abram a apostila. E isso não aconteceu no laboratório com o uso do Processing 2. Antes do início da oficina todos estavam com o aplicativo aberto, vivenciando novas ou velhas experiências.

$\mathrm{Na}$ quarta oficina o grupo estava ansioso por realizar a movimentação dos objetos que aprenderam a construir em Processing 2. O aluno MB mostra para a turma o que ele pesquisou na Internet, em comunidades de programadores (online) sobre o Processing 2, apresentadas no Quadro 5.

Quadro 5 - Pesquisa dos alunos na comunidade na web.

\begin{tabular}{c|l}
\hline MB & $\begin{array}{l}\text { "Professor, eu pesquisei como que faz capturar a posição da coordenada por } \\
\text { meio do mouse". }\end{array}$ \\
\hline P & $\begin{array}{l}\text { "Legal, acredito que vamos precisar disso. Vamos por parte pra gente não se } \\
\text { perder." }\end{array}$ \\
\hline VH & "Eu baixei o Processing!" \\
\hline
\end{tabular}

(Fonte: Primária (2016))

A aprendizagem situada conforme apresentada por Wenger e Lave (1991) prevê trajetórias de participação na comunidade. Impressionante que todos os estudantes manifestaram que tinham realizado download da ferramenta em seus computadores pessoais. 
Os estudantes aprenderam na oficina anterior instruir o computador para desenhar uma forma com local e tamanho específicos. No entanto, um elemento fundamental faltava: a cor. Os estudantes a todo instante perguntavam como inserir cor nos objetos. Era notória a inquietude do grupo em descobrir como colorir seus objetos construídos.

Discute-se que no mundo digital, a cor é definida antes do objeto com um intervalo de números e explica-se o caso mais simples: preto e branco ou tons de cinza, exposto no quadro 6 .

Quadro 6 - Pesquisa dos alunos na comunidade na web.

\begin{tabular}{|c|c|}
\hline $\mathbf{P}$ & $\begin{array}{l}\text { "...temos o seguinte: } 0 \text { significa preto, } 255 \text { significa branco. No meio, qualquer } \\
\text { outro número, um tom de cinza que vai do preto ao branco" }\end{array}$ \\
\hline VH & Professor, tem que ser antes de cada coisa que a gente fizer? \\
\hline MB & $\begin{array}{l}\text { "É como pedir pra alguém fazer um desenho com canetinha, antes tem que } \\
\text { avisar a cor que queremos". }\end{array}$ \\
\hline
\end{tabular}

(Fonte: Primária (2016))

Percebe-se que a busca pelo conhecimento parte da necessidade pontual dos alunos para resolver problemas. Um ambiente de aprendizagem situado fornece um contexto autêntico que reflete a forma como o conhecimento vai ser usado na vida real, a partir de uma necessidade, que preserva o contexto completo da situação sem fragmentação e decomposição, que convida à exploração e permite a complexidade natural do mundo real (WENGER, 2008). Assim, um novo desafio proposto consistia em construir algo semelhante à figura 9.

Figura 9 - Desafio envolvendo formas elementares e cores.

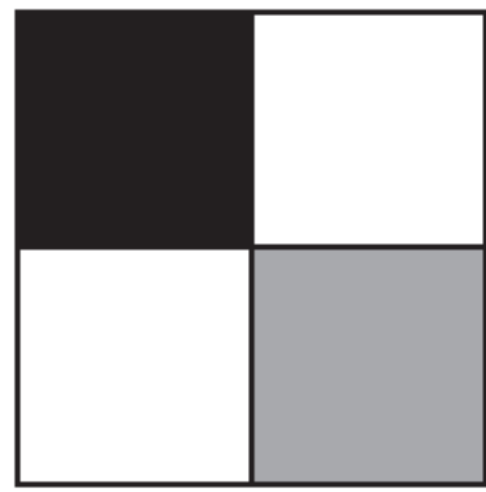

(Fonte: Autor (2016))

Neste desafio, o que chamou atenção foi a utilização de duas estratégias diferentes para atingir o mesmo objetivo. Um ambiente de aprendizagem situada fornece aos estudantes a oportunidade de investigar várias perspectivas (Wenger, 2008). 
Quadro 7 - Estratégia empregada pela aluna TS.

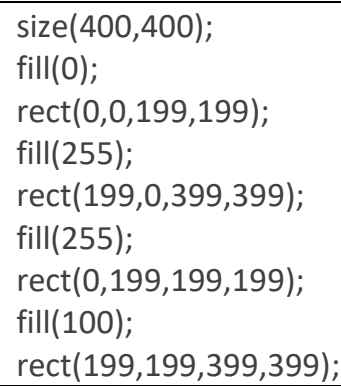

(Fonte: Primária (2015))

A aluna TS solucionou o desafio colocando quadrados justapostos e antes de cada objeto, estipulando a cor desejada para preenchimento (quadro 7). A aluna aproveitou a janela definida no size(). A aluna KA procedeu de forma análoga em sua estratégia.

Interessante destacar que CA atingiu o mesmo objetivo proposto, partindo de uma estratégia diferente. Analisando seu código, o aluno primeiramente traçou um quadrado maior, depois traçou duas linhas perpendiculares e depois sobrepôs aos quadrantes formando dois novos quadrados para conseguir colorir. $\mathrm{O}$ aluno CA conseguiu atingir os objetivos, porém seu código ficou extenso e redundante. $\mathrm{O}$ aluno percebeu que quando criou os quatro quadrantes não conseguiu inserir a cor no preenchimento e como solução realizou a sobreposição.

O professor elogiou o trabalho desenvolvido pelo aluno CA, porém destacou para o grupo que o interessante era fazer um programa com o menor número de códigos, que atendesse aos objetivos, evitando assim desperdício de memória e alcançando um melhor desempenho do programa.

Os alunos VH e NB foram os últimos a terminarem o desafio, pois apresentaram demora nas coordenadas iniciais e finais da construção dos retângulos, descobrindo seus erros por meio da execução do programa. Quando os estudantes compilam seus programas recebem feedback imediato durante as suas experiências, assim reconhecem seus erros e mesuram a distância que estão da meta proposta no desafio. Assim, evidenciamos que para aprender, os estudantes precisam receber, o mais rápido possível, feedbacks claros, específicos e explicativos.

O aluno CA, disse durante conversa com o aluno MB, "...direto no computador fica mais fácil, eu não gosto de fazer no papel". Na resolução dos desafios notouse um desconforto sempre que era necessário fazer uso do papel milimetrado que o pesquisador trouxe para auxiliar no desenvolvimento das atividades. Inicialmente fizeram uso constante do apoio, mas gradualmente foram se desprendendo do papel milimetrado, atuando diretamente no programa. Com isso, a motivação positiva foi percebida na dinâmica da resolução dos problemas à medida que adquiriam autonomia nos processos.

Ainda os alunos insistiam em colorir, para eles o preto, branco e a escala de cinza não satisfaziam a seus anseios. A aluna KA exclamou: "Professor, não quero pôr cinza, quero colocar cor mesmo!", como se as variações de cores apropriadas não fossem cores.

Foi explicado aos alunos sobre a formação das cores digitais que são construídas por meio da mistura de três cores primárias: vermelho, verde e azul 
(RGB). Para formação de uma tonalidade era necessária a combinação de intensidade dessas três cores. A princípio os alunos estranharam e logo questionaram:

VH: “...não posso escrever o nome da cor em inglês? Não funciona?”

NB: “...vamos ter que ficar tentando?"

Assim, foram apresentadas aos alunos duas maneiras para facilitar o trabalho com cores. O Processing 2 possui um seletor de cores para auxiliar na escolha de cores, com acesso via TOOLS (a partir da barra de menus) e também foi possibilitado por meio do editor de imagens (GIMP) do Linux Educacional. Os alunos deram preferência ao aplicativo GIMP por estarem familiarizados com sua utilização. Rapidamente conseguiram compreender a formação das cores e a utilização da ferramenta de auxílio.

Interessante destacar que, imediatamente, os alunos começaram a utilizar o comando fill $(R, G, B)$ em suas criações e, imediatamente, desenharam uma figura geométrica e começaram a testar diversas cores, sem instrução ou comando do professor. Os estudantes conseguiram entender o processo de formação da cor digital e suas combinações e realizavam seus testes. A aluna NB enquanto testava o comando disse "Eu não sabia disso, como é simples". A aluna na verdade estava querendo dizer que ela entendeu o conceito de combinação para se trabalhar com cores, e a partir desse momento aquilo que ela entendia como sendo algo complicado, foi desmistificado e passou a ser algo simples.

Percebe-se que após os alunos descobrirem o mundo das formas primitivas e das cores no padrão RGB, a exploração no Processing 2 começou a ganhar liberdade. Foi notório que, a partir desse momento, o grupo começou a fazer uso da criatividade, que é um passo importante para implementar esses conhecimentos em um cenário de programação do mundo real.

Para os novatos na comunidade de prática em programação, a simplicidade e a interação rápida do Processing 2 foi fundamental para os trabalhos com iniciantes, evidenciado na fala da aluna KA: "Professor, programar é muito animado". Foram contemplados os comandos primitivos em 2D e o comando arc() foi explorado logo na sequência. Nesse momento os alunos começaram a tomar suas ideias e transformá-las em projetos reais de software.

Os estudantes gostavam porque tudo é muito rápido. Nas aulas tradicionais, em muitos momentos os alunos queriam que o professor adiantasse respostas e que o professor resolvesse os problemas propostos na apostila. $\mathrm{O}$ trabalho com a ferramenta foi diferente nesse aspecto, eles queriam ser os protagonistas e resolver seus problemas. CA: "Professor, tá dando erro, mas não fala eu vou descobrir". Nota-se que, com essa geração de estudantes para que se mantenham engajados, o tempo de feedback tem que ser muito curto e o Processing 2 proporciona ricas interações, conforme características da aprendizagem situada apresentadas por Wenger (2000).

Foi disponibilizado um intervalo de 10 minutos aos alunos. Nenhum aluno quis sair do laboratório. Estavam a explorar os conceitos e comandos que estavam dominando de forma livre, mas queriam saber mais. $O$ aluno CA estava assistindo a um vídeo no Youtube sobre Processing 2. A aluna KA descobriu antes de apresentá-los o guia de referências da ferramenta disponível na plataforma digital de apoio. 
Os estudantes começam a explorar os comandos relacionados à cor, e o que estava programado na sequência didática foi adiado para explorar os anseios dos alunos. Percebe-se uma condução não linear, na qual o aluno direciona o que deseja aprender.

No intervalo, os alunos descobriram pesquisando a função background(). A aluna TS disse: "olha aqui, esse comando vai trocar esse fundo cinza". A aluna reconheceu que o fundo padrão é cinza claro e que para definir o plano de fundo ou background necessitava utilizá-lo apenas uma vez. Interessante a rapidez com que todos começaram a testar o comando e como trocavam informações.

Em outro momento, durante a oficina 4, os alunos haviam criado um círculo e o desafio consistia em fazê-lo mover da esquerda para direita bem lentamente na área do sketch. A aluna KA foi a primeira a apresentar o seguinte código (Quadro 8) como solução para o desafio.

Quadro 8 - Estratégia utilizada pela aluna KA no desafio.

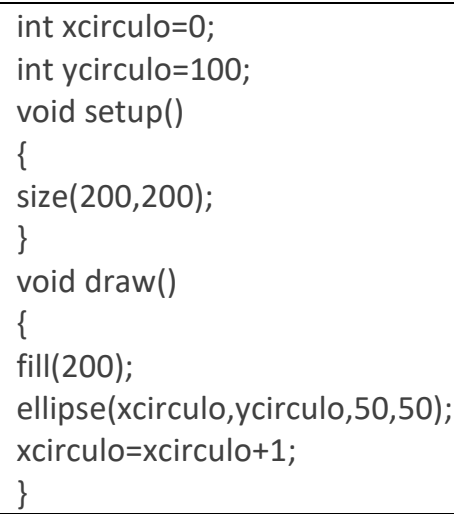

(Fonte: Primária (2015))

A aluna KA não obteve o resultado esperado na execução do programa o que a levou refletir sobre o que poderia estar errado em seu código. O grupo compartilhava da mesma problemática, focados no entendimento do "por que" não estavam obtendo êxito satisfatório. Quando o aluno MB disse "background branco", teve um insight e logo apresentou um código que atendia a sua meta e expressava satisfação. O grupo começou a aumentar a velocidade da movimentação, sem este mediador solicitar, demostrando capacidade de criatividade e domínio do conceito.

Posteriormente foi proposto um desafio em que, em vez de o círculo moverse da esquerda para a direita, o círculo cresceria em tamanho. O aluno VH encontrava dificuldade para alterar a dimensão do diâmetro do círculo, o mesmo só trabalhou com a dimensão horizontal e se esqueceu da dimensão vertical. Como feedback da execução do programa uma elipse deformada era apresentada. 0 aluno MB saiu da sua máquina e foi ajudá-lo a concluir o desafio. Mais uma vez evidenciamos a cultura de colaboração, que encoraja os estudantes, e possibilita estimular o sucesso uns dos outros de forma deliberada. Assim, os estudantes reconhecem que parte do seu propósito é certificar-se de que todos os seus amigos tenham sucesso na resolução do desafio, conforme apontado por Lave e Wenger (1991). situada colaborou para a promoção de uma reflexão que possibilitou abstrações. 
Exigiu que os alunos refletissem sobre uma base muito mais ampla de conhecimento para resolver seu problema.

O quadro 9 traz o programa apresentado pela aluna TS durante a oficina 6 que abordava conceitos de condicionais e o emprego de operadores lógicos matemáticos. Como solução ao desafio apresentado, que tinha como objetivo colorir a uma das quatro regiões do quadrado de acordo com a posição do cursor do mouse.

Quadro 9 - Programa da aluna TS.

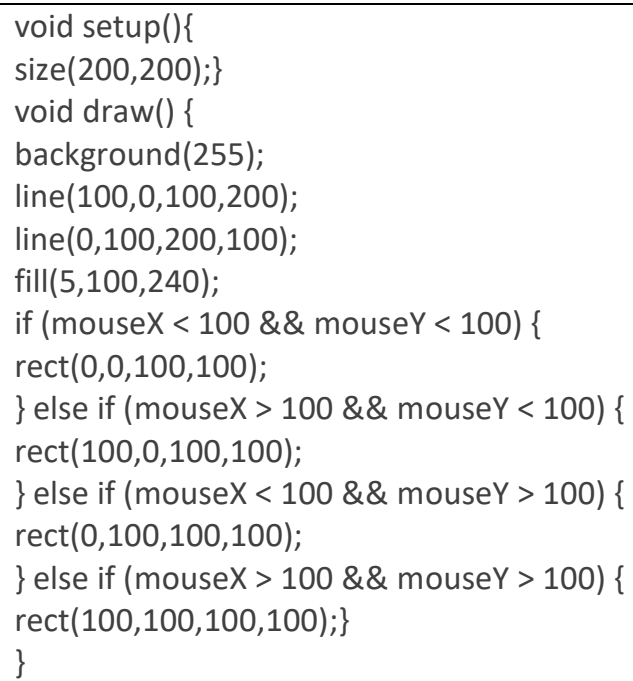

(Fonte: Primária (2016))

Após este desafio o aluno CA teve a ideia de generalizar em outro contexto (Figura 10). Nota-se que quando os alunos são desafiados, transferem o conhecimento para situações diferentes daquela na qual aprenderam um determinado conteúdo.

Figura 10 - Conceito aplicado em outra situação problema (NB).

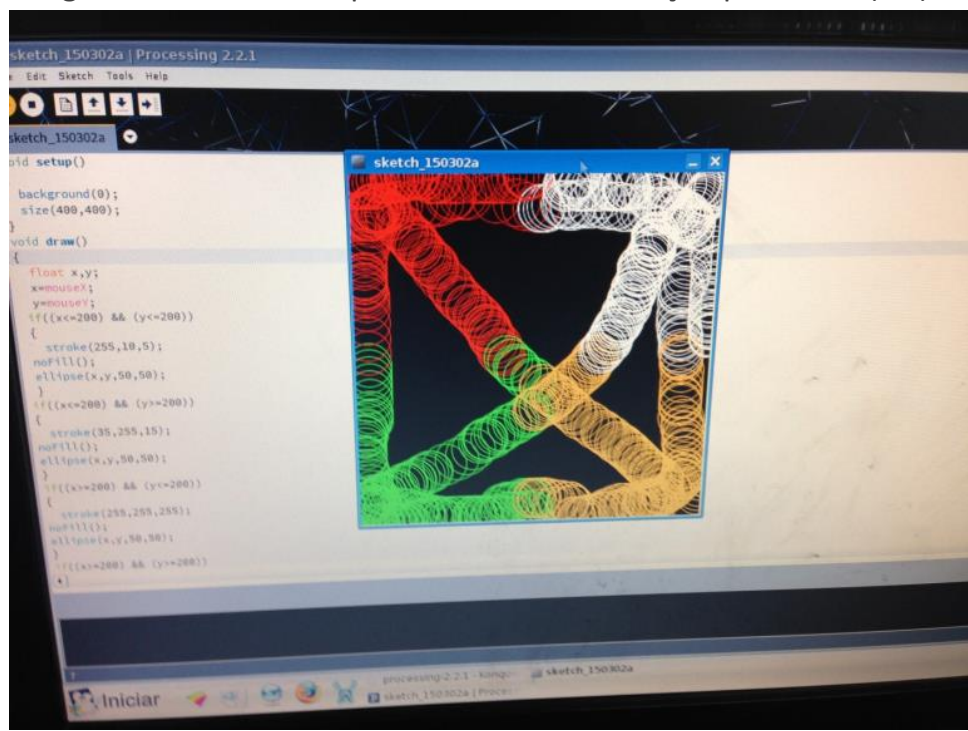

(Fonte: Primária (2016)) 
Assim, surgiu outro desafio a partir da necessidade do aluno, conforme dimensões da aprendizagem situada destacado por Wenger (1998). Nesse contexto, a aprendizagem situada da matemática abordou o conceito de área (região do plano), divisão de áreas, simetria, e os alunos puderam aprimorar suas habilidades de previsão e formalização de hipóteses.

Chegado à escola para ministrar a oficina, alguns alunos já estavam no LIE desvendando o mundo da programação e se aventurando no Processing 2, resolvendo problemas individual e coletivamente que eles mesmos criaram. Notase que os estudantes estavam trabalhando com empenho em suas construções. Alguns construindo programas mais elaborados (aluno $\mathbf{M B}$ ) e outros apenas reproduzindo os desafios anteriores (aluno TS). Isso demostra o engajamento dos estudantes nos processos, enquanto membros periféricos legítimos, realizando uma trajetória que comunica com membros mais experientes da comunidade (WENGER, 1997).

O método torna interessante por possibilitar ao professor trabalhar com o mesmo desafio respeitando o nível cognitivo de cada aluno. O importante é que os alunos estavam a avançar em seus conhecimentos. Não houve ausência e alguns alunos do grupo já destacaram-se como líderes, como os alunos MB, KA e TS. A aprendizagem situada prevê a presença social dentro da comunidade de prática, conforme apontados por Wenger (2000).

Na penúltima oficina com um desafio que consistia em movimentar um círculo para a direita. Para isso era necessário colocar o centro do círculo no ponto central da janela e movimentá-lo para direita com a seta indicativa do teclado. Este desafio teve como objetivo explorar os comandos Keypressed e KeyCode e num primeiro momento, direcionamos a resolução do desafio como forma de andaimes. A aluna KA apresentou a codificação que atendia ao proposto (Quadro 10).

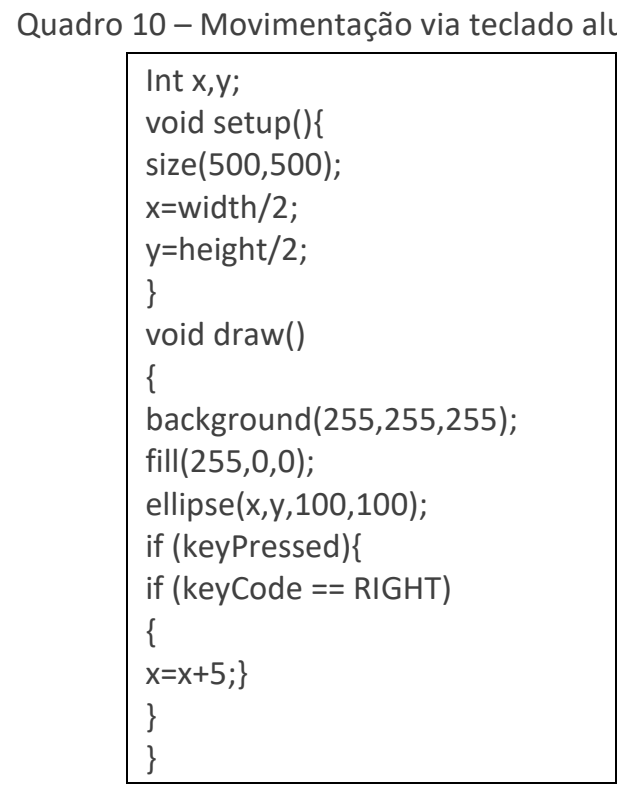

(Fonte: Primária (2015))

Quando os alunos implementaram o programa e começaram os testes, os mesmos apertavam a seta para a esquerda para que o círculo retornasse ao centro. Os alunos percebem que em programação tudo tem que ser indicado passo a passo numa sequência lógica, construindo o algoritmo. 
Depois de apropriados os conceitos anteriormente formalizados, apresentamos novo desafio aos estudantes que tinham como objetivo colocar um retângulo central na parte inferior do sketch e fazê-lo movimentar para a esquerda e para a direta por meio das setas de movimentação.

Para esse desafio, o dividimos em duas partes. Inicialmente criar o retângulo na cor vermelha, central, independentemente do tamanho da área do sketch e na segunda parte da oficina fazê-lo movimentar. Durante a resolução desse desafio o aluno CA disse: "Professor, programar é matemática, isso aqui tudo parece matemática".

Foi a primeira vez, durante as oficinas que os alunos reconheceram a importância da matemática explicitamente, ratificando o pressuposto de Lave e Wenger (1991), em que os compromissos sociais forneceram o contexto adequado para que a aprendizagem ocorresse.

A sistematização do último desafio proposto consistia em fazer uma plataforma que se movimentasse para direita e para esquerda, impedindo uma bolinha de cair, possibilitou que os alunos enxergassem que o importante é quebrar os conteúdos em pequenas partes e explorar cada parte lentamente, uma de cada vez. Dividir um problema de programação em etapas é um bom começo para que ao final tenha algo completo e funcional.

Os alunos perceberam que a cada passo adicionavam uma pequena melhora ao programa: primeiro criaram o retângulo, depois resolveram o problema da movimentação, para então trabalharem na problemática das bolinhas, realizando as devidas animações. Claro que isso é apenas uma pequena fração de todas as etapas de que precisamos para um jogo completo e funcional, mas ele demonstra uma forma importante de pensar.

Essa quebra em etapas facilitou o processo de depuração. Cada vez que testamos os programas, muito provavelmente algo pode não funcionar como o esperado. Assim se começarmos a testar um programa completo, o processo de depuração ficará mais complicado.

São apresentados no quadro 11 alguns extratos de falas dos alunos, que utilizando da análise do conteúdo, pode-se evidenciar características da aprendizagem situada numa comunidade de prática de programadores durante as oficinas.

Quadro 11 - Amostra das falas dos alunos categorizadas de acordo com a sua peculiaridade.

\begin{tabular}{|l|l|l|}
\hline \multicolumn{1}{|c|}{ Peculiaridade } & \multicolumn{1}{|c|}{ Fala dos alunos } & \multicolumn{1}{c|}{ Como foi observado } \\
\hline Ênfase no "saber fazer" & $\begin{array}{l}\text { KA "...esse sistema de } \\
\text { coordenadas a gente usa } \\
\text { em mapas pra gente } \\
\text { localizar os lugares, lá em } \\
\text { casa tem um desse, só que } \\
\text { lá tem as letras e os } \\
\text { números". }\end{array}$ & $\begin{array}{l}\text { Quando os } \\
\text { colações com algo prático, o } \\
\text { interesse é despertado. }\end{array}$ \\
\hline Informal & $\begin{array}{l}\text { VH "Quando não dá erro } \\
\text { dá até uma emoção". }\end{array}$ & $\begin{array}{l}\text { O erro é algo muito natural, } \\
\text { assim } \\
\text { constantemente ocorre } \\
\text { nas }\end{array}$ \\
\hline
\end{tabular}




\begin{tabular}{|c|c|c|}
\hline & & $\begin{array}{l}\text { relações sociais. Na } \\
\text { verdade, fracassar frente a } \\
\text { um desafio proposto foi tido } \\
\text { pelos alunos como uma } \\
\text { coisa boa. A escola } \\
\text { tradicional } \\
\text { oferecer muito menos } \\
\text { espaço para o risco, } \\
\text { exploração e insucesso. } \\
\text { Constatamos que a } \\
\text { ferramenta colaborou nesse } \\
\text { sentido. }\end{array}$ \\
\hline Ênfase no "saber fazer" & $\begin{array}{l}\text { TS: "Preciso de ajuda para } \\
\text { fazer. Alguém conseguiu?" } \\
\text { MB: "Professor, ajuda a } \\
\text { gente nesse aqui". }\end{array}$ & $\begin{array}{l}\text { Um ambiente de } \\
\text { aprendizagem situado prevê } \\
\text { momentos críticos, e os } \\
\text { andaimes de apoio, onde o } \\
\text { professor fornece as } \\
\text { habilidades, estratégias } \\
\text { quando os alunos têm } \\
\text { dificuldades na construção } \\
\text { das ideias do desafio. Aos } \\
\text { poucos, o suporte (o } \\
\text { andaime) é removido até } \\
\text { que o aluno seja capaz de } \\
\text { caminhar sozinho, conforme } \\
\text { apontado por YOUNG } \\
\text { (1993). }\end{array}$ \\
\hline $\begin{array}{ll}\text { Construção } & \text { do } \\
\text { conhecimento parte } & \text { da } \\
\text { necessidade } & \end{array}$ & $\begin{array}{l}\text { MB: "... professor olha que } \\
\text { legal, com isso vou } \\
\text { conseguir fazer um } \\
\text { pacman!". }\end{array}$ & $\begin{array}{l}\text { Foi muito mais interessante } \\
\text { para o grupo, quando a } \\
\text { opção em construir o } \\
\text { Pacman partiu do interesse } \\
\text { e necessidade dos } \\
\text { estudantes naquele } \\
\text { momento. }\end{array}$ \\
\hline Interatividade & $\begin{array}{l}\text { KA: "Professor, programar } \\
\text { é muito animado". }\end{array}$ & $\begin{array}{l}\text { Os estudantes estavam } \\
\text { gostando porque tudo é } \\
\text { muito rápido. O tempo curto } \\
\text { de feedback fez toda a } \\
\text { diferença. }\end{array}$ \\
\hline Engajamento & $\begin{array}{l}\text { NB: "Eu não sabia disso, } \\
\text { como é simples". }\end{array}$ & $\begin{array}{l}\text { Um ambiente de } \\
\text { aprendizagem situado } \\
\text { promove articulação para } \\
\text { permitir o conhecimento } \\
\text { tácito para ser explicitado. } \\
\text { Lave e Wenger (1991) } \\
\text { apontam que ser capaz de } \\
\text { falar o vocabulário e contar } \\
\text { as histórias de uma cultura } \\
\text { de prática é fundamental } \\
\text { para a aprendizagem. }\end{array}$ \\
\hline
\end{tabular}

(Fonte: Autor (2016))

A análise do conteúdo possibilitou uma percepção polissêmica, o que permitiu a este pesquisador qualitativo uma abundância de interpretações. Assim, esse quadro representa apenas uma pequena amostra do trabalho realizado. 
Aprender o básico em programação ajudou iniciar os alunos na nova alfabetização do século e treiná-los em projetos que envolvam colaboração. 0 Processing 2 se mostrou adequado aos novatos numa comunidade de prática de programação, pela sua simplicidade e por sua dinâmica visual, permitindo aos estudantes transformar suas ideias em projetos reais de software.

O emprego do método não favoreceu somente a dimensão técnica, mas a dimensão humana, política e social evidenciando a multidimensionalidade do processo de ensino e aprendizagem.

Outro ponto, observado é em relação ao tempo. Trabalhar com a ferramenta, requer, com certeza, mais tempo para ensinar. Mas, antes de considerar o tempo dispendido para que os alunos aprendam é preciso considerar a qualidade da aprendizagem. A aprendizagem situada por meio da ferramenta tem característica não linear e gerou indagações não previstas pelo professor e, nesse sentido, o ensino poderá demandar mais tempo que o previsto. Em contrapartida, muitas vezes, o uso do Processing 2, por facilitar a aprendizagem gera ganho de tempo. A reutilização do código foi fundamental, o que possibilitou agilizar muitos momentos do processo de aprendizagem.

Os alunos dispunham de uma pasta individual para guardarem seus programas e outra pasta compartilhada com todos. Assim, os alunos poderiam acessar a qualquer instante, e também potencializar o tempo de aprendizagem.

A aprendizagem situada numa comunidade de prática possibilitou ampliar a linguagem e promover a comunicação de ideias matemáticas; apropriar estratégias de resolução de problemas; gerar a capacidade de fazer estimativas, cálculos mentais; abstrair, organizar e planejar ações. Também estimulou a concentração (foco), perseverança e a criatividade. Promoveu a troca de ideias e contribuiu para a compreensão de regras, percepções no plano cartesiano, e principalmente para a formação de conceitos.

Percebe-se que, à medida que avançam nas oficinas, os alunos aumentam sua atitude reflexiva e questionadora. Uma observação do processo de execução permitiu constatar que os alunos foram levados à análise, de modo que eles construíam (ênfase no fazer), encontravam seus erros, procuravam corrigi-los, testavam.

A construção do saber matemático na superação dos baixos índices de rendimento de nossos alunos requer também conhecimentos externos à matemática. As novas demandas sociais educativas apontam para a necessidade de um ensino voltado para a promoção do desenvolvimento da capacidade de ação e reflexão e o Processing 2 veio colaborar com tais desenvolvimentos, conforme apontados por Almeida (2000).

Além disso, conseguimos ratificar algumas das dimensões dos pressupostos teóricos apresentados por Lave e Wenger (1991) e Wenger (1998) na aprendizagem situada, quando se trabalha com Processing 2, entre eles: alta interatividade dos alunos e mediadores (pesquisador e computador), uma aprendizagem mais colaborativa voltada à construção do conhecimento compartilhado, presença social (líderes), estado reflexivo processual, a formação de uma cultura de sala de aula onde todos os estudantes são tratados como talentosos e com potencial, bem como a formação de uma identidade, por meio 
de alunos apaixonados por programação e fascinados pelas possibilidades de criação em Processing 2.

Quando os estudantes não obtinham sucesso em suas estratégias, direcionávamos o desafio. Assim, na resolução dos desafios quando um aluno não chegava próximo ao objetivo, não havia em nenhum momento a expressão "você está errado". Os questionamentos recorrentes eram: "De que outra maneira podemos olhar para isso, de forma a atender a meta?" ou até mesmo: "Essa é um boa resposta, mas não é exatamente o objetivo que temos que alcançar no desafio"

O ambiente de aprendizagem situada, utilizando Processing 2 possibilitou também uma avaliação holística da aprendizagem, por meio de uma avaliação autêntica, que está relacionada com o processo e com engajamento dos estudantes na comunidade de prática.

Foi ainda possível evidenciar, algumas dimensões decorrentes de se aprender situado, apoiado por ferramentas de programação como o Processing 2 , conforme Figura 11.

Figura 11- Dimensões observadas.

\begin{tabular}{|c|c|}
\hline Autonomia & $\begin{array}{l}\text { CA : "Agora a gente já sabe, pode } \\
\text { parar". } \\
\text { "Professor, tá dando erro, mas nãofala } \\
\text { eu vou descobrir". }\end{array}$ \\
\hline Cooperação & $\begin{array}{l}\text { TS: "Vamos deixar mais rápido, sabe } \\
\text { comofaz? Vou explicar". (lideres) }\end{array}$ \\
\hline $\begin{array}{c}\text { Erro como elemento } \\
\text { natural }\end{array}$ & $\begin{array}{c}\text { MB "Eu fiz um de cada, mas olha aqui } \\
\text { vou arrumar porque o triângulo ficou } \\
\text { sobreo meu retângulo". }\end{array}$ \\
\hline Imediatismo & CA: "Roda de novo pra gente vê". \\
\hline $\begin{array}{c}\text { Assimilação de conceitos } \\
\text { Matemáticos }\end{array}$ & $\begin{array}{c}\text { TS: "[...]isso aquié duas circunferências } \\
\text { tangentes, porque ela se encontra só } \\
\text { nesse ponto". }\end{array}$ \\
\hline
\end{tabular}

(Fonte: Autor (2016))

Assim, a autonomia, cooperação, o erro como elemento natural, imediatismo, assimilação de conceitos matemáticos foram dimensões evidenciadas quando se utiliza a programação de computadores como instrumento didático-pedagógico.

Aproveitou-se a oportunidade para conversar com a professora de matemática dos estudantes que estava em seu horário de estudo (Quadro 12). 


\begin{tabular}{c|l}
\hline $\mathbf{P}$ & $\begin{array}{l}\text { "Professora, a senhora notou alguma diferença no grupo de alunos } \\
\text { participantes deste projeto? }\end{array}$ \\
\hline $\mathbf{A C}$ & $\begin{array}{l}\text { "Eu percebi que os alunos passaram a se dedicar mais nas aulas de } \\
\text { matemática, e o MB, o CA, e a TS mudaram muito sua postura em sala de aula, } \\
\text { estão mais envolvidos com o processo, principalmente no retorno da tarefa de } \\
\text { casa". }\end{array}$ \\
\hline $\mathbf{P}$ & "Mais alguma coisa que a senhora queira comentar, sinta-se à vontade." \\
\hline $\mathbf{A C}$ & $\begin{array}{l}\text { "Outra coisa, eles comentavam nas aulas sobre o que estavam aprendendo no } \\
\text { curso. Até na reunião de pais a mãe do M perguntou como que fazia para o } \\
\text { filho participar, porque os amiguinhos disseram que estavam gostando muito } \\
\text { do curso. Mas quando selecionei o grupo, apontei outros alunos que se } \\
\text { enquadravam no perfil que você solicitou, mas não quiseram, agora estão } \\
\text { querendo participar". }\end{array}$ \\
\hline
\end{tabular}

(Fonte: Primária (2016))

Quando o aluno esquece o dever de casa, nós enquanto docentes, exclamamos "Então você esqueceu o dever de casa de novo" e tachamos de irresponsáveis. Mas dificilmente perguntamos qual estratégia podemos tentar para ajudá-lo a entregar o dever de casa na data solicitada. Com o Processing foi diferente como pudemos evidenciar na fala da professora.

Fomos buscar uma relação para os nomes citados pela professora e notamos que são justamente aqueles alunos que se transformaram numa espécie de mentores (líderes) durante as oficinas para ajudar os outros integrantes do grupo, que estenderam essa postura para além das atividades no LIE.

Percebemos pela fala da professora que o número de alunos que quer participar das oficinas de programação aumentava à medida que os alunos comentavam sobre suas experiências no Processing.

A condução das oficinas estava sempre cheia de novos pensamentos, conversas, novas ideias. Nas pequenas pausas realizadas, os alunos mantinham o foco no assunto e objetivos. A pesquisa demostra um incentivo a investir em métodos pedagógicos assistidos por tecnologia, que quando usados e avaliados de forma apropriada, melhoram a aprendizagem de maneira significativa.

Outro fator notável é a potencialização do tempo gasto para os alunos receberem suas correções. Durante as oficinais percebeu-se a motivação dos alunos em receberem um feedback rápido. Com a apostila, um assunto é explorado e solicita-se a realização da tarefa de casa e só então num outro momento é realizada a correção. Com o uso do Processing 2 o retorno rápido aos alunos foi um diferencial.

Os alunos se sentem frustrados porque geralmente demoram em média algumas aulas para receberem as correções das atividades da apostila. Isso significa que o professor não percebe de imediato se o conteúdo de um módulo teve seus conceitos e habilidades dominados pelos alunos, não podendo sanar suas dúvidas.

A avaliação passou a ser dinâmica e o professor pode concentrar sua aula nas maiores dúvidas e passar mais rapidamente pelas habilidades já contempladas. A aprendizagem situada por meio das oficinas de programação contribuiu para o 
fluxo de acordo com as necessidades reais dos alunos mantendo a dosagem entre os eixos habilidades e dificuldades conforme apontados por Csikszentmihalyi (2009).

A aversão à língua inglesa evidenciada no grupo focal inicial, na codificação se tornou interessante e prazerosa, uma vez que os alunos ampliavam seus vocabulários naturalmente na comunidade de prática de programação em Processing 2 e a aprendizagem de programação contribuiu para que os alunos reconhecessem a importância do idioma no mercado de computação, onde as ferramentas de programação, manuais, referências são desenvolvidas na sua grande parte em língua inglesa. Assim, as oficinas de programação contribuíram para que os estudantes ampliassem suas visões no tocante à importância do domínio da língua inglesa nos dia de hoje.

Assim, é possível entender que a aprendizagem situada da matemática, inserida numa comunidade de prática de programadores contribui para formar uma comunidade escolar que realmente prepara alunos para a cultura global do século XXI, envolvendo a nova alfabetização apontada por Prensky (2008) e Resnick (2013).

\section{CONCLUSÃO}

A utilização do Processing 2 possibilitou ampliar a linguagem e promover a comunicação de ideias matemáticas, adquirir estratégias de resolução de problemas e planejamento de ações, cálculos mentais e abstração.

Foi possível evidenciar que no transcorrer das oficinas os alunos passaram a perceber a necessidade e a importância da matemática enquanto constroem programas que representam seus anseios e desejos. Assim, o conhecimento parte da necessidade pontual e com isso explora uma aprendizagem mais ativa. A programação de computadores articulada com a resolução de problemas possibilitou a sistematização e apropriação de conceitos matemáticos. Na construção de algoritmos para solução dos desafios, precisaram entender e compreender os conceitos matemáticos envolvidos nessa construção e a programação passou a ser um suporte. Os estudantes deixaram de ser meramente receptores de informações, e se engajaram de maneira ativa nas práticas da comunidade, o que contribuiu para uma aprendizagem ativa.

Os alunos não saíram experts em programação após as oito oficinas, mas tiveram uma ideia mais precisa do que é e como deve ser construído um programa de computador. Enquanto os alunos trabalhavam no desenvolvimento dos projetos, como eles mesmos declararam, criando as sequências de comandos, eles estavam a aprender sobre o processo de construção; de como começar uma ideia; de como discuti-la com o grupo e como transformá-la num projeto completo e funcional.

Os alunos puderam direcionar o andamento das aulas e os conteúdos a serem trabalhados pelo professor para possibilitar a resolução de seus desafios. Alguns estudantes se destacaram como líderes, e se transformaram numa espécie de mentor para ajudar outros integrantes do grupo, com o compromisso mútuo de equivalência entre todas as partes envolvidas nos processos sociais, construindo uma identidade que direciona para a solidariedade e ajuda mútua, fruto de uma prática que propicia a horizontalidade. 
Conforme a discussão dos dados mostrou, a programação de computadores como instrumento didático-pedagógico, no emprego da ferramenta Processing 2 possibilitou a promoção de trabalho mais cooperativo, que coloca o erro como elemento natural no processo de aprendizagem, e torna a aprendizagem mais interativa, com feedback imediato, o que contribuiu para apropriação de conceitos matemáticos adjacentes da atividade de programação.

A discussão dos dados mostra, em vários momentos, vantagens de aulas de matemática utilizando ferramentas de programação como o Processing 2 , com ricas situações de aprendizagem. $O$ trabalho realizado nas oficinas de programação foi articulado à solução de problemas, assim, o método de ensino foi modificado. Não há aluno ruim que não avance, mas uma escola e métodos talvez ineficientes e incompatíveis com os objetivos desse século. Para melhorar essa situação acredita-se que o método pode ser uma das respostas.

O desafio é escolher ou desenvolver métodos interessantes e lembrar que não existe um método bom para todos os alunos, bem como um aluno adequado para qualquer método; o correto é a oferta de um pluralismo metodológico. Pensa-se que há uma relação método/aluno, o mais difícil é saber exatamente qual. Assim, acredita-se que um dos fatores está relacionado à interatividade e no tempo rápido de respostas conforme evidenciado neste trabalho.

As dificuldades ao desenvolver aulas de matemática utilizando ambiente de programação Processing 2 foram elencadas. Entre elas, a mudança filosófica na postura do professor, juntamente com os tipos de mudanças que o uso de ferramentas de programação provocou na dinâmica das aulas de matemática, com a formação de líderes.

A programação é considerada uma habilidade difícil de aprender. No entanto, se for apoiada por estratégias de ensino adequadas e ferramentas de Tecnologia da Informação, podem ser dominadas pelos alunos. Assim, este trabalho conseguiu identificar talentos naqueles que são ignorados ou taxados de ruins (baixo rendimento em matemática) e provou a tese de que com um pouco de coerência, dedicação e vontade podemos transformar a educação matemática, na busca da superação dos baixos índices de rendimento. 


\title{
Programming in teaching math using Processing 2: a study of formalized relations for elementary students with low performance in mathematics
}

\begin{abstract}
This qualitative study investigated in a community of programmers practice the relations formalized by students with low achievement in mathematics, before, during and after participating in programming workshops. By means of legitimate peripheral participation, the aim was to show how students perceive the necessity and / or importance of mathematics while they are programming, what mathematical concepts are appropriate in this construction, the relationships established, and the difficulties and / or difficulties during this process. The research consisted of eight workshops and used the tool Processing 2. From the situated learning we outlined six categories of analysis and tried to find subsidies to answer other questions such as: What are the advantages of math classes using programming tools? While the students worked on solving the challenges, they were "programming to learn". As the workshops progressed, the students increased their reflective attitude, so the tool became only a support.
\end{abstract}

KEYWORDS: Programming education. Problem solving. Mathematical thinking. Situated learning. 


\section{REFERÊNCIAS}

ALMEIDA, Maria Elizabeth Bianconcini. Informática e formação de professores. Brasília: Ministério da Educação, 2000, 1 v.

BARDIN, Laurence. Análise de Conteúdo. Lisboa, Portugal: Edições 70, 2011.

BATISTA, Adriana Correia Almeida. Aprendizagem Situada em uma comunidade de aprendizes de matemática de uma escola pública. 2014, 223p. Tese (Doutorado em Educação). Programa de Pós-Graduação em Educação da Unicamp, Área de concentração: Ensino e Práticas Culturais, Eixo: Prática Pedagógica em Matemática. Campinas, SP; Universidade Estadual de Campinas.

BLOOMBERG. Why Schools in England Are Teaching 5-Year-Olds How to Code. (2014). Disponível em: <http://www.bloomberg.com/news/print/2014-1015/why-schools-in-england-are-teaching-5-year-olds-how-to-code.html>. Acesso em: 10 jan. 2015.

CARVALHO, Isamir M.; STEIL, Andrea Valéria. Aprendizagem Tradicional e Aprendizagem Situada em Organizações: uma Reflexão relacionada aos Tipos de Aprendizagem. In: Eneo 2012 - Encontro de Estudos Organizacionais, 2012, Curitiba/PR. Anais EnEO 2012. Rio de Janeiro: ANPAD, 2012.v. 1.

CSIKSZENTMIHALYI, Mihaly. Flow The Psychology Of Optimal Experience. New York: Collins Publishers, 2009.

FERNANDES, Elza Maria dos Santos. Aprender matemática para viver e trabalhar no nosso mundo. 2004, 479p. Tese de doutorado: Departamento de Educação da Faculdade de Ciências de Lisboa. APM. Lisboa.

GATTI, Bernadete Angelina. Grupo focal na pesquisa em ciências sociais e humanas. 1. ed. Brasília: Líber Livro, 2005.

HALVERSON, Richard. Rethinking education in the age of technology. New York: Teachers College Press, 2009.

INEP. Relatório Nacional Pisa 2012: Resultados brasileiros. (2014). Disponível em: <http://download.inep.gov.br/acoes_internacionais/pisa/resultados/2014/relato rio_nacional_pisa_2012_resultados_brasileiros.pdf.>. Acesso em: $10 \mathrm{dez} .2015$. practice: Perspectives on Activity and Context. Cambridge: University of Cambridge Press, 1993. 
LAVE, Jean.; WENGER, Etienne. Situated Learning: Legitimate Peripheral Participation. Cambridge: Cambridge University Press, 1991.

PAPERT, Seymour. Logo: computadores e educação. São Paulo: Brasiliense, 1986.

PRENSKY, M. Teaching digital natives: partnering for real learning. California: Corwin, 2010. Disponível em <http://marcprensky.com/wpcontent/uploads/2013/04/Prensky-TEACHING_DIGITAL_NATIVESIntroduction1.pdf>. Acesso em: 19 mar. 2015.

PRENSKY, M. The True Twenty-first Century Literacy is Programming. In: Edutopia, feb. 2008. Disponível em <http://www.edutopia.org/literacycomputer-programming>. Acesso em: 10 fev. 2015.

PRENSKY, Marc. Listen to the Natives. In: Educational Leadership. v. 63. n. 4. 2005. p.8-13. Disponível em:

<http://www.ascd.org/ASCD/pdf/journals/ed_lead/el200512_prensky.pdf>. Acesso em 15 mar. 2015.

PROCESSING. (2015). Processing. Disponível em:

<http://https://www.processing.org/>. Acesso em: 03 jan. 2015.

RESNICK, Mitchel. Learn to Code, Code to Learn. 2013. Disponível em: < http://web.media.mit.edu/ mres/papers/L2CC2L-handout.pdf>. Acesso em: 20 dez. 2014.

RESNICK, Mitchel. Scratch: Programming for All. 2009. Disponível em: <http://web.media.mit.edu/ mres/papers/Scratch-CACM-final.pdf>. Acesso em: 20 dez. 2014.

RESNICK, Mitchel. Vamos ensinar as crianças a escrever códigos. 2012. Disponível em:

<http://www.ted.com/talks/mitch_resnick_let_s_teach_kids_to_code?language= pt-br\#t-19466>. Acesso em: 22 jan. 2015.

RUSHKOFF, Douglas. As 10 questões essenciais da era digital. São Paulo: Editora Saraiva, 2012.

SARESP. Secretaria da Educação do Estado. Relatório Pedagógico Matemática SARESP 2014. 2015. Disponível em < http://file.fde.sp.gov.br/saresp/saresp2014/Arquivos/RELATORIO_PEDAGOGICO_ MATEMATICA.pdf>. Acesso em: 28 nov. 2015. 
SETTI, M. DE O. G. O Processo de discretização do raciocínio matemático na tradução para o raciocínio computacional: Um Estudo de Caso no Ensino/Aprendizagem de Algoritmos. Tese (Doutorado em Educação). Curitiba: UFPR, 2009.

WENGER, Etienne. Communities of practice and social learning systems: the career of a concept. 2000. Disponível em < http://wenger-trayner.com/wpcontent/uploads/2012/01/09-10-27-CoPs-and-systems-v2.01.pdf>. Acesso em: 10 mar. 2015.

WENGER, Etienne. Communities of practice: Learning, meaning and identity. New York: Cambridge University Press, 1998.

WING, Jeannette M. Computational thinking and thinking about computing. Philosophical Transactions of the Royal Society, 2008. Disponível em: < https://www.cs.cmu.edu/ CompThink/papers/Wing08a.pdf>. Acesso em: 18 dez. 2015.

WING, Jeannette M. Computational thinking. Communications of the acm. v. 49. n. 3, 2006. Disponível em: < https://www.cs.cmu.edu/ 15110-s13/Wing06ct.pdf>. Acesso em: 18 dez. 2015.

\footnotetext{
Recebido: 2017-04-01

Aprovado: 2017-07-18

DOI: 10.3895/rbect.v11n1.5766

Como citar: SOUZA, E. C.; YONEZAWA, W. M. Programação no ensino de matemática utilizando Processing 2: Um estudo das relações formalizadas por alunos do ensino fundamental com baixo rendimento em matemática. Revista Brasileira de Ensino de Ciência e Tecnologia, v. 11, n. 1, 2018. Disponível em:

<https://periodicos.utfpr.edu.br/rbect/article/view/5766>. Acesso em: xxx.

Correspondência: Eduardo Cardoso de Souza - eduardoc@fc.unesp.br Direito autoral: Este artigo está licenciado sob os termos da Licença Creative Commons-Atribuição 4.0 Internacional.
} 